\title{
Mangelnde Arbeitsmoral?
}

\section{Junge Ärzte kämpfen gegen Vorurteile älterer Kollegen}

\author{
Dass Nachwuchsmediziner ihr Bedürfnis nach Freizeit über die Nöte \\ ihrer Patienten stellen und zu hohe Anforderungen an Ausbilder und \\ Arbeitgeber haben, ist reines Schubladendenken, finden junge Ärzte - \\ und fordern ein neues Arbeitsklima.
}

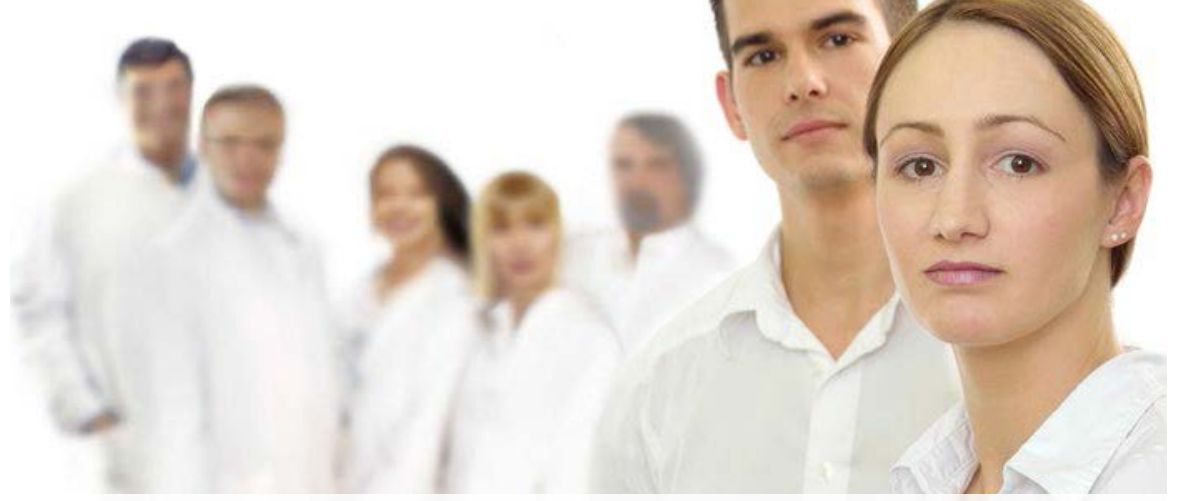

Flache Hierarchien und Teamarbeit fördern die Arbeitsmoral nicht nur junger Ärzte.

E rfahrene Ärzte sind immer im Dienst, leben für ihre Arbeit und bringen zahlreiche Opfer für ihre Patienten - auch zulasten ihres privaten Zeitbudgets. Junge Ärzte streben eine Karriere nur an, wenn es sich mit der Freizeit vereinbaren lässt. Arzt sein ist für sie Beruf, nicht Berufung. So oder ähnlich lauten gängige Klischees, wenn über die vermeintlich unterschiedlichen Einstellungen der Ärzte-Generationen diskutiert wird.

Weiterbildungsassistent und Sprecher vom Bündnis Junge Ärzte Dr. Kevin Schulte ist solcher Vereinfachungen überdrüssig. „Es ist Quatsch, dass uns die persönliche Freiheit wichtiger wäre als die Patientenversorgung. Ich wehre mich gegen diese Vorwürfe und Vorurteile“, sagte er bei der Nationalen Branchenkonferenz Gesundheitswirtschaft in Rostock. „Die Nachwuchsmediziner, die in Klinik und Praxis ihren Dienst leisten, sind hoch motiviert.“
Erfahrene Ärzte zeigten, dass sie die jungen Kollegen durchaus differenziert betrachten. Viele sind in ihrer Aus- und Weiterbildungszeit selbst mit Vorurteilen über ihre Arbeitsmoral konfrontiert worden. Prof. Wolfgang Motz vom Klinikum Karlsburg brachte die Stimmung, die seine Generation früher von den damals etablierten Kollegen $\mathrm{zu}$ spüren bekam, auf den Punkt: „Entweder macht man gute Medizin, oder man geht früh nach Hause.“ Ähnliches bekommen junge Ärzte auch heute zu hören. Hat sich also gar nicht so viel geändert?

Es gibt einen Wandel, aber zum Positiven. So speist sich die Autorität eines Chefs heute mehr aus seinem fachlichen Können, weniger aus seiner Position. Flache Hierarchien werden selbstverständlicher. Früher dagegen war der Chef laut Motz nicht nur eine Instanz, vor dem Chef hatte man Angst. Ein weiterer Unterschied: Die Arbeit im Krankenhaus war früher deutlich entspann- ter. Mit der zunehmenden Arbeitsverdichtung sei der Ausgleich, auf den junge Ärzte heute Wert legten, unverzichtbar und berechtigt, so Motz.

Auf der anderen Seite müssen junge Ärzte auch bereit sein, sich mit Kritik, Enttäuschung und Niederlagen auseinanderzusetzen. Nach Beobachtung von Prof. Christian Schmidt, ärztlicher Vorstand der Universitätsmedizin Rostock, kommen junge Ärzte oft mit extrem hohen Erwartungen, die in der Realität nicht erfüllbar sind. Daraus erwachsen dann Frust und Enttäuschung.

\section{Oft mangelt es an Perspektiven}

Warum junge Ärzte vielleicht nicht immer so enthusiastisch sind wie andere erwarten, könnte aber auch an fehlenden Perspektiven liegen. Schulte gab zu bedenken, dass das Gesundheitssystem in Deutschland immer wieder gerne als das Beste, das man kenne, dargestellt wird trotz nicht zu übersehbarer Schwächen. Jungen Ärzten wird oft vermittelt, dass man froh sein könne, wenn dieses $\mathrm{Ni}$ veau gehalten wird. „Wer hat schon Lust, alles dafür zu tun, damit alles so bleibt, wie es ist?", fragte Schulte und forderte: „Wir brauchen Ziele und Visionen.“

Daran könne jeder Einzelne mitwirken. Wer Verbesserungsvorschläge junger Kollegen mit dem Spruch „Das haben wir schon immer so gemacht" abschmettere, dürfe nicht mit Enthusiasmus rechnen. Kliniken, die neue Kollegen in der Personalabteilung mit der Aussage „Wir sind hier nicht bei ,Wünsch Dir was', sondern bei ,So ist es ““ begrüßen, zeigten wenig Bereitschaft für ein Arbeitsklima, in dem Aufgeschlossenheit und Flexibilität eine zentrale Rolle spielen. Nur wenn diese Bereitschaft vorhanden sei, könne auch generationsübergreifend an Lösungen für Verbesserungen gearbeitet werden. Dirk Schnack 